Categoria

Trabalho Acadêmico\Resumo Expandido

Titulo do Trabalho

\title{
LIXÃO INATIVO DA CIDADE DE ILHA SOLTEIRA: ANÁLISE AMBIENTAL E PROPOSTA DE REMEDIAÇÃO
}

Nome do Autor (a) Principal

Larissa Yumi Cavazzana

Nome (s) do Coautor (a) (s)

Rafaela Souza Schiapati

Nome (s) do Orientador (a) (s)

Jairo Salim Pinheiro de Lima

Instituição ou Empresa

Universidade Estadual Paulista "Júlio de Mesquita Filho"

Instituição (s) de Fomento

E-mail de contato

Iyumic@gmail.com

Palavras-chave

Remediação. Lixão. Resíduos Sólidos.

\section{INTRODUÇÃO}

Os resíduos sólidos dispostos inadequadamente poluem o solo e comprometem a qualidade das águas superficiais e subterrâneas, com implicações à saúde humana e ao 
meio ambiente. Estudos indicam que a gestão integrada de resíduos sólidos e os processos de tecnologia limpa são maneiras ambientalmente corretas e economicamente viáveis. Os principais problemas na gestão de resíduos sólidos urbanos são o crescimento desordenado na geração e a destinação final. A Política Nacional de Resíduos Sólidos (Lei nº12.305) em 2010, que criou diretrizes que regulamentam essas operações e definem prazos, como a desativação de todos os lixões até 2014, cobrando uma postura muito diferente daquela adotada por muitos municípios, como em Ilha Solteira - SP.

\section{OBJETIVO GERAL}

Este trabalho consistiu em analisar a situação atual do antigo lixão do município de Ilha Solteira - SP, e lançar propostas de gestão para remediação adequada ao caso, conciliando os aspectos legais, ambientais e econômicos acerca do assunto.

\section{OBJETIVOS ESPECÍ́FICOS}

O trabalho teve como finalidade investigar a história do sistema de gerenciamento dos resíduos sólidos urbanos em Ilha Solteira, analisar a situação atual do lixão existente na cidade, identificando os principais riscos ambientais e à saúde da população humana e propor alternativas de gestão para a remediação do lixão inativo do município.

\section{METODOLOGIA}

As atividades de pesquisa e investigação científica estão fundamentadas na legislação vigente e em procedimentos definidos e publicados em literatura específica, como: Normas NBR e ABNT, Leis Federais, Estaduais e Municipais, livros científicos, manuais de Gestão Ambiental e relatórios e trabalhos científicos. 


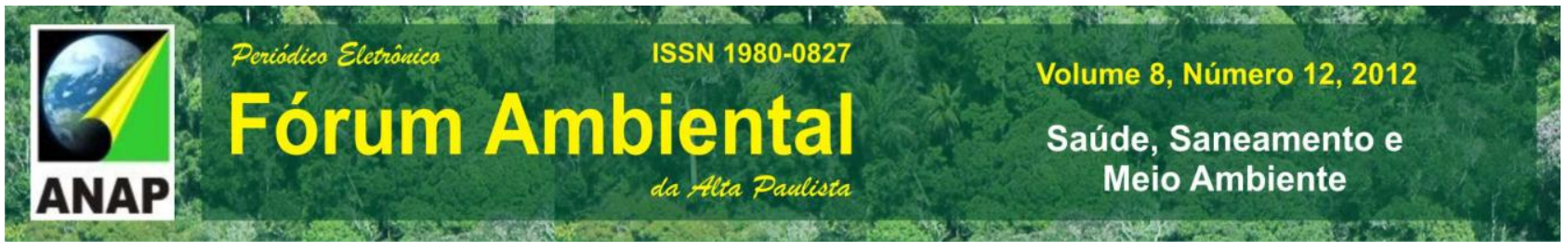

Também se obteve informações e dados acerca da situação atual do lixão de llha Solteira por meio de documentos e entrevistas em órgãos públicos e instituições relacionadas ao tema. Foram realizadas também visitas técnicas aos locais destinados à administração e gestão pública de temas ambientais no município e ao atual lixão (desativado).

\section{RESULTADO (S)}

\section{Levantamento Histórico e situação atual}

Com base em informações obtidas, o local do antigo lixão era usado desde 1970 como disposição final dos RSU, porém foi legalmente apropriado a partir de 1981, conforme metas estabelecidas pelo projeto original de aterro sanitário, desenvolvido pela CETESB. Contudo, o local se transformou em um misto entre lixão e aterro controlado. Findadas as atividades de despejo em dezembro de 2008, período em que o novo aterro sanitário foi inaugurado, a área do antigo lixão foi coberta com solo e compactado.

De fato, o lixão não está oficialmente desativado, uma vez que faz parte dos procedimentos para a obtenção das licenças ambientais no aterro sanitário (também sem o devido licenciamento). Esta condicionante foi determinada pela CESTEB, órgão licenciador no Estado de São Paulo.

Não se obtiveram informações da quantidade e classificação dos resíduos depositados no antigo lixão, cujos documentos foram perdidos, segundo o órgão de gerenciamento do lixo municipal.

Foi feito um plano de encerramento e remediação para a área do antigo lixão em 2008, ao mesmo tempo em que se fez o projeto do novo aterro sanitário, ambos aprovados, pois atendiam a legislação da época. Executou-se o projeto do aterro, adiando o do encerramento do lixão. Quando a legislação mudou, o plano de remediação caducou e passou a não satisfazer as normas vigentes. Tais condições resultaram no declínio do IQR (Índice de Qualidade de Aterro dos Resíduos) do município, que passou de 9,2 em 2009 para 7,9 em 2010, mudando a caracterização de "adequado" para "controlado" (CETESB). 


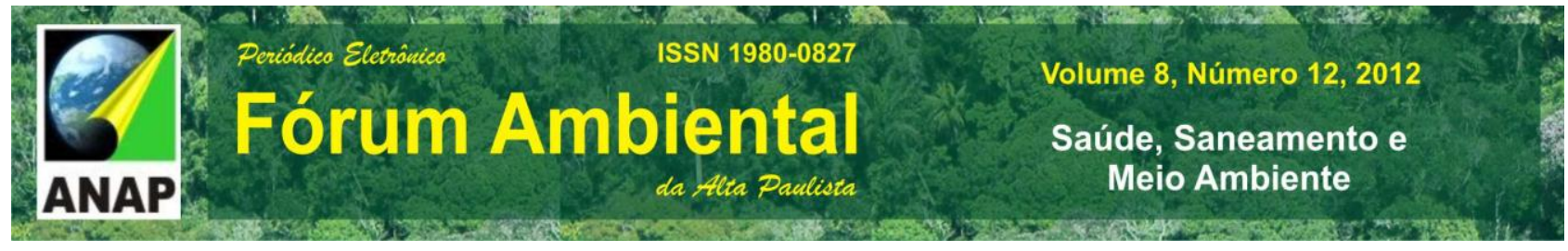

Em 2006, a Política Estadual dos Resíduos Sólidos (Lei nำ12.300) não tinha grande vigor por não encontrar embasamento na legislação federal consolidada. A partir de agosto de 2010 foi outorgada a Lei nำ12.305 que instituiu a Política Nacional dos Resíduos Sólidos (PNRS) dando poder a todos os instrumentos relacionados à Gestão Ambiental. Nessa lei observa-se o rigor quanto às obrigações, mas não oferece mecanismos para a execução dessas exigências. Outro aspecto observado na PNRS é que a lei prioriza a disposição ambientalmente adequada dos resíduos, porém é inadimplente com as áreas que já foram degradadas. Apesar das lacunas encontradas na lei federal, o Decreto no 7.404 de dezembro de 2010 complementou-a, ressaltando que até 2014 todos os lixões deverão ser devidamente encerrados.

O antigo lixão está a 2,3 km da entrada Norte do município, beirando a rodovia SP 310. Em seu entorno encontram-se um posto de combustível e diversos galpões com funções variadas (reciclagem de materiais, produção de ferramentas para usinagem, produção de blocos para construção, artigos de floricultura e outros).

Por meio de observações diretas em campo, não foram identificadas desestabilização de talude nem locais com percolação de chorume. Não se notou possíveis contaminações do lençol freático que abastece a população. Constatou-se que há liberação de gases contaminantes na atmosfera e presença de catadores/moradores em áreas próximas ao lixão. Não foram relacionadas diretamente as queimadas que ocorreram na área remediada com a presença de gases e líquidos tóxicos. Também não se associou a presença de vetores na região como oriundas da área do lixão. Observouse que no local não há nenhum controle e/ou equipamento de monitoramento. Vê-se, portanto, que a área do antigo lixão encontra-se desprovida de manutenção e monitoramento, sem um fim adequado e sem fiscalização.

\section{Propostas para remediação do antigo lixão}

Teoricamente, a maneira correta de recuperar a área degradada por um lixão seria proceder à remoção completa do lixo ali depositado, colocando-o num aterro sanitário e recuperando a área escavada com solo natural da região. Contudo, os custos envolvidos nesses procedimentos são muito elevados e inviabilizam, economicamente, esse procedimento. Seja a disposição final dos RSU em lixões uma forma inadequada, 
têm-se duas alternativas: remediação do lixão ou transformação do lixão em aterro sanitário (que é a forma mais adequada de disposição final dos RSU).

A remediação consiste no processo que objetiva reduzir, o máximo possível, os impactos negativos causados pela disposição inadequada do lixo urbano no solo, considerando-se a decisão de terminar a operação no local. Junto do encerramento desse local deve-se realizar um estudo das alternativas de novos locais para disposição de lixo, de modo que não seja inviabilizada a disposição deste, em curto prazo, no município (IPT/CEMPRE). Para isso, devem-se escolher as ações necessárias para encerramento da operação e a remediação do local, estabelecendo uma lista de prioridades, definindose as ações principais, as que demandem menores custos e prazos e maiores impactos ou resultados mais positivos.

Como não foi possível uma avaliação com informações suficientemente relevantes, sugere-se uma avaliação das condições de comprometimento ambiental do lugar. Isso pode ser feito por análises das águas superficiais e subterrâneas e sondagens para conhecer o estágio de decomposição dos resíduos e das condições de estabilidade e permeabilidade do solo. Com essas ações determinam-se as vias potenciais de transporte dos contaminantes e os riscos ambientais à população e ao ambiente (NERS).

Em seguida, sugere-se organizar atividades remediadoras com os objetivos de reduzir a mobilidade, toxidade e o volume dos contaminantes e estabilizar o solo de maneira prática, lógica e economicamente viável. Consideram-se as etapas de tratamentos físico e químico e o monitoramento ambiental da área (ALBERTE).

Para o tratamento dos resíduos sólidos, após a inertização, o material estabilizado pode ser removido e peneirado, possibilitando a reutilização do espaço, enquanto a fração orgânica pode ser utilizada como material de cobertura. Os subprodutos do peneiramento podem, por sua vez, ser comercializados nas indústrias e na agricultura.

Já para tratar os resíduos gasosos, basicamente, destroem-se os contaminantes gasosos por meio da combustão controlada, cuja execução faz-se fora da célula, por meio de sistema de extração forçado e destruição térmica dos componentes orgânicos do biogás à baixa temperatura.

O tratamento dos resíduos líquidos tem por objetivo impedir a percolação de contaminantes pelo solo, minimizando sua atuação impactante nos aquíferos 
subterrâneos. As técnicas de tratamento assemelham-se àquelas utilizadas para 0 esgoto, como remoção dos sólidos por cloro, lodo ativado, biofilme e lagoas aeradas.

Além dos resíduos, ressalta-se o tratamento das águas superficiais do aterro, que devem limitar a percolação e maximizar a remoção dessas águas. Sugere-se o dimensionamento de lagoas de retenção para águas pluviais.

Após o encerramento e recuperação do lixão, é necessária a conformação da superfície final e dos taludes. Em seguida, procura-se fazer a revegetação da área, cujo objetivo é minimizar a erosão por meio do rápido estabelecimento das raízes.

A recuperação do lixão não é encerrada somente com essas obras. A manutenção dos dispositivos de segurança e controle é importante para a eficácia das instalações. O chorume acumulado nos poços de reunião, por exemplo, deve ser recirculado para dentro da massa de lixo periodicamente, por meio de aspersores ou de leitos de infiltração. Os poços de gás necessitam de vistorias periódicas, reacendendo aqueles que forem apagados por ventos ou chuvas. E a qualidade da água subterrânea precisa ser controlada por poços de monitoramento implantados, assim como as águas superficiais e de corpos hídricos próximos (IBAM/SEDU).

\section{CONSIDERAÇÕES FINAIS}

Por meio do levantamento histórico e atual da gestão de RSU do município, notaram-se as necessidades de fiscalização e de complementações das leis vigentes, de forma que os órgãos de gestão e administração pública municipal efetivem as propostas de melhoria do meio ambiente. Ademais, vê-se a necessidade de um Plano de Resíduos Sólidos Municipal parece imperativo à boa gestão das demandas ambientais e práticas sustentáveis.

No estudo de alternativas para a remediação, observou-se a escassez de materiais com especificações técnicas a essa ação. Também se viu a necessidade de atualização e inovação de métodos para remediação de áreas degradadas, em manuais e cartilhas específicas. 


\section{REFERÊNCIAS}

Alberte, E. P. V.; Carneiro, A. P.; Kan, L. (2005). Recuperação de áreas Degradadas por Disposição de Resíduos Sólidos Urbanos.

Companhia de Tecnologia de Saneamento Ambiental (CETESB), Deutsche Gesellschaft fur Technische Zusammenarbeit (GTZ). (2001). Manual de gerenciamento de áreas contaminadas. $2^{\mathrm{a}}$ edição. São Paulo.

D'Almeida, M. L. O. et. al. (2000). Lixo municipal: manual de gerenciamento integrado. Instituto de Pesquisa Tecnológica do Estado de São Paulo - IPT/CEMPRE. $2^{\mathrm{a}}$ edição. São Paulo.

Monteiro, J. H. P. et al. (2001). Gestão Integrada de Resíduos Sólidos: Manual de Gerenciamento Integrado de Resíduos Sólidos. Instituto Brasileiro de Administração Municipal - IBAM/SEDU. $2^{\text {a }}$ edição. Rio de Janeiro.

Núcleo de Estudos de Resíduos Sólidos (NERS) (2003). Remediação do Lixão dos Carreiros. Fundação Universidade Federal do Rio Grande. 